Kumi Nakamura MD, Hiroshi Toda MD, Yoshio Hatano MD, ${ }^{*}$ Kenjiro Mori MD FCAnaes

\title{
Comparison of the direct effects of sevoflurane, isoflurane and halothane on isolated canine coronary arteries
}

We have demonstrated previously, using dog epicardial arteries of different sizes, that isoflurane, like adenosine, is preferentially a small coronary artery dilator, whereas halothane, like nitroglycerin, is a large artery dilator. The present study was designed to compare the direct effects of sevoflurane with those of isoflurane and halothane. Proximal large coronary arteries with an outer diameter (o.d.) of 2.5-3.2 $\mathrm{mm}$ and distal small arteries of $0.6-0.9 \mathrm{~mm}$ o.d. were isolated from dogs and then cut into vascular rings. They were precontracted with $\mathrm{KCl}(20 \mathrm{mM})$, and their relaxant responses to anaesthetics were compared relative to the maximal responses induced by papaverine. Sevoflurane, halothane and isoflurane (1-3 human MAC) induced dose-dependent relaxation of these arteries. The relaxant response to sevoflurane did not differ between large and small arteries. However, the relaxant response of the large arteries to halothane (1.5-2.3\%) was greater than that of small arteries $(P<0.01)$ and the response of small arteries to isoflurane (3.5\%) was greater than that of large arteries $(P<0.05)$. In large arteries, the potency of the relaxant effect at equivalent human MAC could be ranked as halothane $\geq$ sevoflurane $>$ isoflurane, and, in small epicardial arteries as isoflurane $>$ sevoflurane $\gg$ halothane. We conclude that, unlike isoflurane, sevoflurane is not a preferential dilator of small coronary arteries.

\section{Key words}

ANAESTHETICS, VOLATILE: halothane, isoflurane, sevoflurane; ARTERIES: coronary; HEART: blood flow, myocardial.

From the Department of Anesthesia, Kyoto University Hospital and *Department of Anesthesiology, Wakayama Medical College.

Address correspondence to: Dr. K. Nakamura, Department of Anesthesia, Kyoto University Hospital, Sakyo-ku, Kyoto 606-01, Japan.

Accepted for publication 9th November, 1992.
Nous avons déjà démontré sur des artères canines épicardiques de différents calibres, que lisoflurane, comme l'adénosine est un dilatateur préférentiel des petites artères coronaires, alors que lhalothane, comme la nitroglycérine, est un dilatateur des grosses artères. L'étude présente vise à comparer les effets directs du sévoflurane avec ceux de lisoflurane et de l'halothane. Chez le chien, on isole et sectionne en anneaux de grosses artères coronaires d'un diamètre externe de 2,5 à 3,2 $\mathrm{mm}$ et des petites artères coronaires distales de 0,6 à $0,9 \mathrm{~mm}$. Elles sont préalablement contractées avec du $\mathrm{KCl}(20 \mathrm{mM})$ et leurs propriétés relaxantes en présence d'anesthésiques sont comparées à la réponse maximale provoquée par la papavérine. Il ny a pas de différence entre le sévoflurane, l'halothane et lisoflurane (MAC 1-3 humain); ils provoquent tous une relaxation artérielle qui dépend de la dose. L'effet relaxant du sévoflurane est identique que ce soit sur les grosses ou les petites artères. Cependant, la relaxation des grosses artères en réponse à lhalothane (1,5-2,3\%) est plus importante que celle des petites artères $(P<0,01)$ et la réponse des petites artères à l'isoflurane (3,5\%) est plus marquée que celle des grosses artères $(P<$ 0,05). Pour les grosses artères, la puissance de l'effet relaxant à un MAC humain équivalent pourrait être classifiée dans l'ordre: halothane $\geq$ sévoflurane $>$ isoflurane; et sur les petites artères épicardiques ainsi: isoflurane $>$ sévoflurane $\gg$ halothane. Nous concluons que contrairement à lisoflurane, le sévoflurane n'est pas un dilatateur préférentiel des petites artères coronaires.

Although several in vivo studies have reported the effect of sevoflurane on organ blood flow, there is no agreement concerning its effect on coronary blood flow, ${ }^{1-5}$ and its ability to induce coronary steal. ${ }^{6,7}$ Sevoflurane was initially shown to decrease coronary blood flow in pigs by Monohar and Park, ${ }^{1}$ and, later, Akazawa et al. ${ }^{2}$ and Conzen et al. ${ }^{3}$ obtained similar results in dogs and rats, respectively. However, Bernard et al. ${ }^{4}$ and Crawford et al. ${ }^{5}$ observed increases of coronary flow induced by se- 
voflurane in dogs and rats, respectively. This discrepancy may, in part, be due to differences in experimental conditions, since in vivo findings are inevitably affected by changes in systemic haemodynamics, myocardial metabolism or contractility, the effects of other anaesthetics administered concurrently and the level of $\mathrm{PaCO}_{2}$. The last will be altered by depression of respiration or artificial ventilation. Therefore, in vitro study was undertaken to clarify the direct effect of sevoflurane on coronary arteries.

Furthermore, it is known that a preferential dilator of large epicardial arteries or resistance vessels may induce quite different changes in myocardial oxygenation in patients with coronary artery disease. Dilatation of epicardial vessels may relieve coronary spasm and increase collateral flow to the ischaemic area, whereas dilatation of the resistance vessels may induce coronary steal and worsen myocardial ischaemia. ${ }^{8}$ Numerous studies have indicated that isoflurane is a preferential dilator of small vessels in the coronary circulation and may induce coronary steal. ${ }^{9-13}$ The aim of the present study was to evaluate the direct effect of sevoflurane on coronary arteries of different sizes in vitro. The effects of isoflurane and halothane were included in order to evaluate the potential of sevoflurane to induce coronary steal in comparison with other anaesthetics.

\section{Methods}

The protocol was approved by the Kyoto University Animal Use Committee. Ten male mongrel dogs weighing 8-15 $\mathrm{kg}$ were anaesthetized with ketamine, $20 \mathrm{mg} \cdot \mathrm{kg}^{-1}$ $\dot{N}$, and then killed by bleeding from the common carotid arteries. The heart was removed rapidly and the left anterior descending and circumflex branches of the left coronary artery were isolated. The proximal portions of these branches with outer diameters (o.d.) of $2.5-3.2 \mathrm{~mm}$ and distal portions of $0.6-0.9 \mathrm{~mm}$ o.d. were used for the study. Although helical strips of these arteries had been prepared previously, ${ }^{12}$ in the present study, the coronary arteries were cut into rings $3.5-4.5 \mathrm{~mm}$ long in order to obtain a larger number of preparations with similar o.d. from a single animal for comparison of the effects of three anaesthetics. The arterial rings were fixed between hooks in a 10-ml organ bath containing Krebs' bicarbonate solution which was aerated with a mixture of $5 \% \mathrm{CO}_{2}$ and $95 \% \mathrm{O}_{2}$ and maintained at $36.5-37.5^{\circ} \mathrm{C}$. The composition of Krebs' bicarbonate solution was (in $\mathrm{mM}$ ) was $\mathrm{NaCl}, 118.2: \mathrm{KCl}, 4.6: \mathrm{NaHCO}_{3}, 24.8: \mathrm{CaCl}_{2}$, 2.5: $\mathrm{MgSO}_{4}, 1.2: \mathrm{KH}_{2} \mathrm{PO}_{4}, 1.2$ : dextrose, 10 , and the $\mathrm{pH}$ was 7.35-7.45 when aerated with the gas mixture. Isometric contractions and relaxations were displayed on an oscillograph (Nihondenki-Sanei Co., Tokyo, Japan). Resting tension was adjusted so that maximal contraction

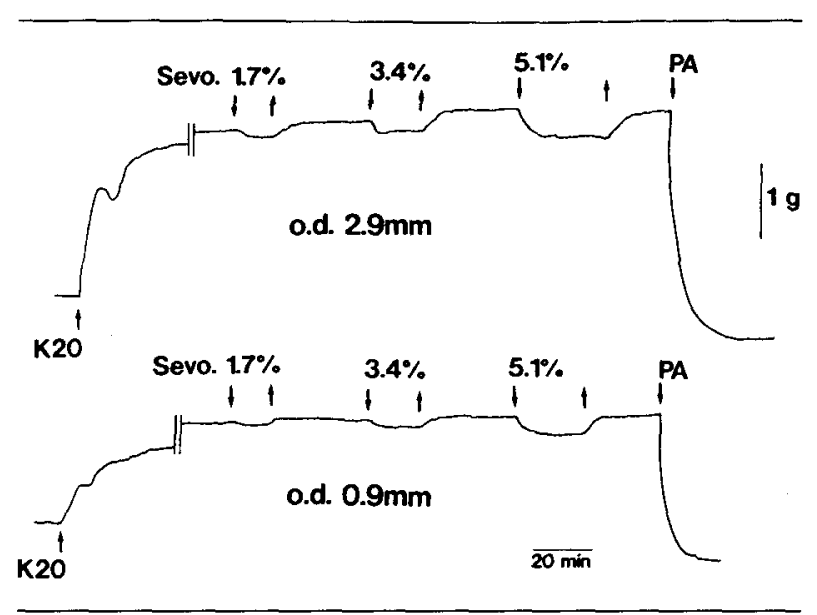

FIGURE 1 Typical recordings of changes in tension induced by sevoflurane $(1.7,3.4$ and $5.1 \%$ ) in vascular strips of large and small epicardial arteries contracted with $20 \mathrm{mM} \mathrm{KCl}$. K20, KCl $20 \mathrm{mM}$; Sevo, sevoflurane; PA, Papaverine $\left(10^{-4} \mathrm{M}\right)$.

occurred with $40 \mathrm{mM} \mathrm{KCl}$. The rings were allowed to equilibrate for $60-90 \mathrm{~min}$ in the control solution, with fluid replacement every $15 \mathrm{~min}$. Endothelial integrity was confirmed chemically by relaxant responses to $10^{-6} \mathrm{M}$ acetylcholine in $\mathrm{KCl}(20 \mathrm{mM})$-contracted rings. ${ }^{14}$ In a preliminary study, relaxant responses of large arteries (o.d. $\geq 2.5 \mathrm{~mm})$ to nitroglycerin $\left(10^{-7}-10^{-5} \mathrm{M}\right)$ were greater than those of small arteries (o.d. $\leq 0.9 \mathrm{~mm})(P$ $<0.05$ ), and responses of small arteries to adenosine $\left(10^{-4} \mathrm{M}\right)$ were greater than those of large arteries $(P<$ 0.05 ).

After contraction with $20 \mathrm{mM} \mathrm{KCl}$ had been stabilized the rings were exposed to anaesthetic at 1-3 MAC (human $\mathrm{MAC}^{15-17}$ ) for longer than ten minutes until the tension had been stabilized again. One anaesthetic was administered to each ring, and the order of application of each concentration was randomized. Vascular rings in which stabilization could not be achieved were excluded from the study.

The MAC values differ among species ${ }^{18}$ because of differences in the sensitivity of the central nervous system to the anaesthetic or with distribution among organs. There is no reason to suppose that the sensitivity of vascular smooth muscle to the anaesthetic is altered by the difference in MAC among species. Therefore, in the present and previous ${ }^{12}$ in vitro studies, we compared the effects of anaesthetics on canine arteries at equivalent human MAC values. ${ }^{18}$

Sevoflurane, halothane and isoflurane were introduced in the gas mixture through agent-specific vaporizers $\left(\mathrm{PPV}_{\Sigma}\right.$, Penlon, England for sevoflurane, Fluotec 3, Ohmeda, England for halothane and Fortec, Ohmeda for isoflurane). The concentration in the resulting gas mixture 


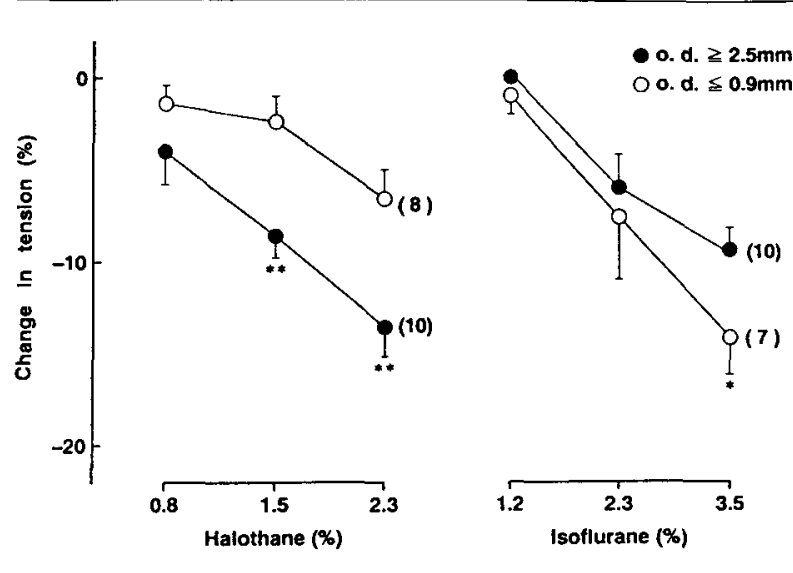

FIGURE 2 Tension changes induced by halothane (0.8-2.3\%) and isoflurane (1.2-3.5\%) in large (o.d. $\geq 2.5 \mathrm{~mm}$ ) and small (o.d. $\leq 0.9$ $\mathrm{mm}$ ) epicardial arteries. Values in parentheses indicate the numbers of vascular rings studied. The absolute values of relaxation induced by $10^{-4} \mathrm{M}$ papaverine (taken to be $100 \%$ relaxation) averaged $2483 \pm 266$ $\mathrm{mg}(n=20)$ in large arteries and $842 \pm 115 \mathrm{mg}(n=15)$ in small arteries. ${ }^{*} P<0.05$ and ${ }^{* *} P<0.01$ large artery vs small artery.

was monitored and adjusted using an Atom 303 anaesthetic agent monitor (Atom, Tokyo, Japan). The actual concentrations of these anaesthetics in the bathing solution were determined by gas chromatography (Hewlett Packard 5890A Gas Chromatography, Avondale, PV). The concentration of anaesthetics solved in the bathing solution was stabilized within ten minutes; they were 7.38 $\pm 0.63 \mathrm{mM}(n=6), 1.01 \pm 0.16 \mathrm{mM}(n=3)$ and $0.72 \pm 0.12 \mathrm{mM}(n=3)$ for $3.4 \%$ sevoflurane, $1.5 \%$ halothane and $2.3 \%$ isoflurane, respectively. At the end of each experiment, papaverine $\left(10^{-4} \mathrm{M}\right)$ was added to the bathing solution, and the changes in tension induced by each concentration of anaesthetic were expressed as percentages relative to the maximal relaxation induced by papaverine.

Values are expressed as means \pm SEM. The responses of large versus small arteries were compared by Student's $t$ test for unpaired data. Other data were analyzed by analysis of variance and the SNK test. Differences of $P<0.05$ were considered significant.

Drugs used were sevoflurane (Maruishi Pharmaceutical Co., Osaka, Japan), halothane (Takeda Pharmaceutical Co., Osaka), isoflurane (Dainabot, Osaka) and papaverine hydrochloride (Dai-nippon Pharmaceutical Co., Osaka).

\section{Results}

Sevoflurane (1.7-5.1\%), halothane $(0.8-2.3 \%)$ and isoflurane (1.2-3.5\%) induced dose-dependent relaxations of arteries of both sizes (Figures 1-3). Relaxation induced by halothane at $1.5-2.3 \%$ was greater in large arteries

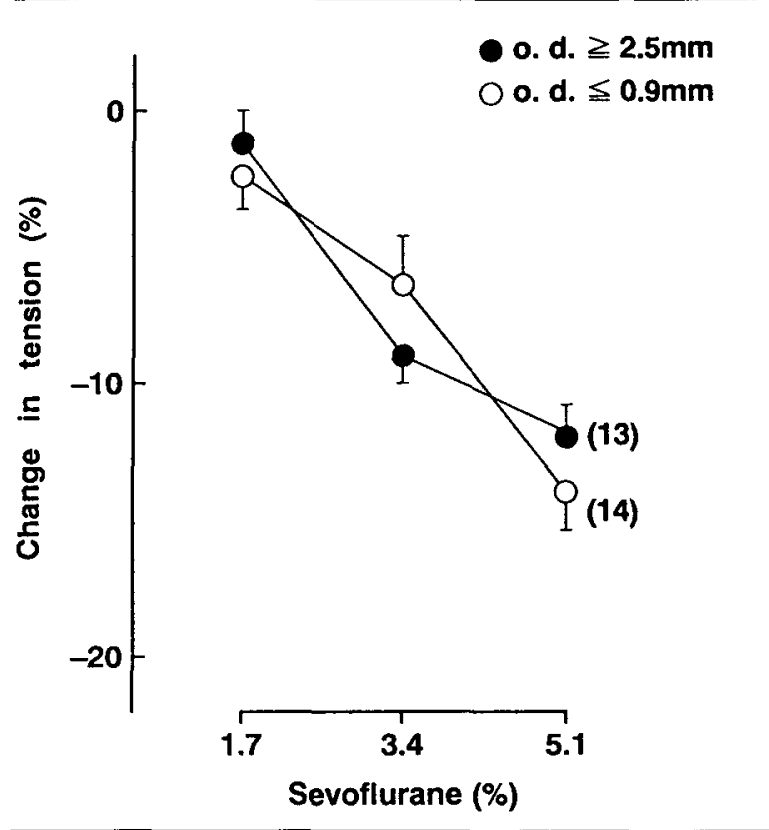

FIGURE 3 Tension changes induced by sevoflurane $(1.7-5.1 \%)$ in large (o.d. $\geq 2.5 \mathrm{~mm}$ ) and small (o.d. $\leq 0.9 \mathrm{~mm}$ ) epicardial arteries. Values in parentheses indicate the numbers of vascular rings studied. The absolute values of relaxation induced by $10^{-4} \mathrm{M}$ papaverine (taken to be $100 \%$ relaxation) averaged $2978 \pm 266 \mathrm{mg}(n=13)$ in large arteries and $920 \pm 139 \mathrm{mg}(n=14)$ in small arteries.

than in small ones, and relaxation induced by $3.5 \%$ isoflurane was greater in small arteries than in larger ones (Figure 2). In contrast, the magnitude of relaxation induced by sevoflurane $(1.7-5.1 \%)$ was not different between small and larger arteries (Figure 3).

When the effects of the three anaesthetics at equivalent human MAC were compared, the relaxant potencies on large arteries were ranked in the order halothane $=$ sevoflurane $>$ isoflurane at $2 \mathrm{MAC}$, and halothane $>$ sevoflurane $>$ isoflurane at $3 \mathrm{MAC}$. The relaxant potencies on small arteries were isoflurane $>$ sevoflurane $\gg$ halothane at 2 and 3 MAC.

\section{Discussion}

Although epicardial arteries, even those of small diameter, differ from resistance vessels in terms of structure and function, in vitro small epicardial arteries often show reactivity to vasoactive agents similar to that of resistance vessels in vivo. ${ }^{19,20}$ Miwa and Toda ${ }^{20}$ compared the susceptibility of isolated dog epicardial arteries of different sizes to the relaxant effect of adenosine, a well-known preferential dilator of resistance vessels in vivo. ${ }^{21}$ They showed that the rank order of relaxation induced by adenosine was distal artery (o.d. less than $0.3 \mathrm{~mm}$ ) $>$ medium artery (o.d. $0.5-0.8 \mathrm{~mm}$ ) $>$ proximal artery (o.d. greater than $1.5 \mathrm{~mm}$ ). Similarly, in our previous study, ${ }^{12}$ 
we showed that isolated epicardial arteries of o.d. less than $0.9 \mathrm{~mm}$ were more susceptible to the effect of adenosine, and less susceptible to nitroglycerin, than proximal, larger epicardial arteries, suggesting that the reactivity of the small epicardial arteries (o.d. $\leq 0.9 \mathrm{~mm}$ ) used in our previous and present studies is similar to that of resistance vessels.

The present findings on the effects of halothane and isoflurane on vascular rings of dog epicardial arteries were similar to our previous findings on helical strips of such arteries; ${ }^{12}$ halothane was a preferential dilator of large epicardial arteries and isoflurane was a preferential dilator of small ones. These results suggest that isoflurane, like adenosine, is a dilator of resistance vessels. Recently, Conzen et al. ${ }^{13}$ provided further evidence for this hypothesis by demonstrating with epiillumination and fluorescence microscopy that isoflurane at a clinically relevant concentration $(1.5 \pm 0.14 \%)$ dilated epicardial arteries with an initial o.d. of 20-120 $\mu \mathrm{m}$ in situ.

In contrast to isoflurane, the direct effect of sevoflurane on isolated coronary artery has not been reported. Thus, this is the first in vivo study which demonstrated that sevoflurane dilates KCl-contracted coronary arteries dosedependently. Moreover, it demonstrated that the magnitudes of relaxation induced by sevoflurane do not differ between large and small epicardial arteries. This indicates that sevoflurane, unlike isoflurane, is not a preferential dilator of small coronary arteries, and suggests that the dilator effect of sevoflurane on resistance vessels of the coronary circulation is less than that of isoflurane. This is consistent with previous in vitro findings in that sevoflurane-induced decrease in coronary vascular resistance was less prominent than that induced by isoflurane. ${ }^{3,4}$ Similar findings were reported using the isolated rat heart by Larach and Schuler. ${ }^{6}$

Drug-induced dilatation of resistance vessels increases blood flow to healthy regions of myocardium, although blood flow to ischaemic areas, in which resistance vessels are already maximally dilated, cannot be increased further. Thus, preferential dilators of resistance vessels such as dipyridamole can cause coronary steal and may worsen coronary ischaemia in patients who have collateraldependent ischaemic regions. ${ }^{8}$ Therefore, the present findings suggest that the ability of sevoflurane to induce coronary steal is, even if it exists, less than that of isoflurane. The in vivo finding of Monohar and Parks ${ }^{1}$ and Cork et al. $^{7}$ that the subendocardial/subepicardial perfusion ratio was not altered by sevoflurane, whilst isoflurane has been reported to decrease this ratio, ${ }^{7,11}$ also supports this hypothesis.

Dilatation of large coronary arteries, in contrast to that of resistance vessels, would be beneficial to patients with angina who have spasm of the large epicardial arteries or organic coronary artery stenosis with the ischaemic area perfused through collateral flow. The present study revealed that halothane over $0.8 \%$ (1 MAC) and sevoflurane over $3.4 \%$ (2 MAC) are dilators of large coronary arteries. However, the magnitudes of relaxation induced by anaesthetics up to the highest concentration tested were much smaller than those induced by vasodilators such as nitroglycerin. Therefore, based on the present in vitro findings, it seems unlikely that these anaesthetics exert any important beneficial effect on myocardial oxygenation in patients with coronary artery disease.

The present study examined the effect of anaesthetics on $\mathrm{KCl}$-contracted arteries alone and did not examine the effect on arteries contracted with vasoactive agonists. We have recently demonstrated in human platelets that halothane specifically inhibits binding of thromboxane $\mathrm{A}_{2}$ analogue to its binding site. ${ }^{22}$ Therefore, one may suppose that the potential of anaesthetics, particularly halothane, to ameliorate coronary spasm may be greater than their potential to dilate KCl-contracted artery, if formation of thromboxane $A_{2}$ was involved in the aetiology of vasospasm. Further study is required to test this hypothesis.

In conclusion, the dilator effect of sevoflurane does not show preference for large or small epicardial arteries in an in vitro model. Thus, we speculate that sevoflurane is less likely to induce coronary steal than isoflurane in patients with coronary artery disease.

\section{References}

1 Manohar M, Parks CM. Porcine systemic and regional organ blood flow during 1.0 and 1.5 minimum alveolar concentrations of sevoflurane anesthesia without and with 50\% nitrous oxide. J Pharmacol Exp Ther 1984; 231: 640-8.

2 Akazawa S, Shimizu R, Kasuda H, Nemoto K, Yoshizawa Y, Inoue $S$. Effects of sevoflurane on cardiovascular dynamics, coronary circulation and myocardial metabolism in dogs. Masui 1988; 2: 227-41.

3 Conzen PF, Vollmar B, Habazettl H, Frink EJ, Peter K, Messmer $K$. Systemic and regional hemodynamics of isoflurane and sevoflurane in rats. Anesth Analg 1992; 74 : 79-88.

4 Bernard J-M, Wouters PF, Doursout $M-F$, Florence B, Chelly $J E$, Merin RG. Effects of sevoflurane and isoflurane on cardiac and coronary dynamics in chronically instrumented dogs. Anesthesiology 1990; 72: 659-62.

5 Crawford $M W$, Lerman J, Pilato $M$, Orrego $H$, Saldivia V, Carmichael FJ. Haemodynamic and organ blood flow responses to sevoflurane during spontaneous ventilation in the rat: a dose-response study. Can J Anaesth 1992; 39 : $270-6$. 
6 Larach $D R$, Schuler $H G$. Direct vasodilatation by sevoflurane, isoflurane, and halothane alters coronary flow reserve in the isolated rat heart. Anesthesiology 1991; 75: 268-78.

7 Cork RC, DiNardo JA, Hilwig RW, Kern KB. Endo/epicardial flow ratio with sevoflurane compared to other volatile agents. Anesthesiology 1991; 75: A505.

8 Gross GJ, Warltier DC. Coronary steal in four models of single or multiple vessel obstruction in dogs. Am J Cardiol 1981; 48: 84-92.

9 Priebe $H$-J. Differential effects of isoflurane on regional right and left ventrical performances, and on coronary, systemic, and pulmonary hemodynamics in the dog. Anesthesiology 1987; 66: 262-72.

10 Sill JC, Bove AA, Nugent $M$, Blaise $G A$, Dewey $J D$, Grabau $C$. Effects of isoflurane on coronary arteries and coronary arterioles in the intact dog. Anesthesiology 1987; 66: 273-9.

11 Buffington CW, Romson JL, Levine A, Duttlinger NC, Huang $A H$. Isoflurane induces coronary steal in a canine model of chronic coronary occlusion. Anesthesiology 1987; 66: 280-92.

12 Hatano $Y$, Nakamura $K$, Yakushiji T, Nishiwada M, Mori $K$. Comparison of the direct effects of halothane and isoflurane on large and small coronary arteries isolated from dogs. Anesthesiology 1990; 73: 513-7.

13 Conzen PF, Habazett H, Vollmar B, Christ $M$, Baier $H$, Peter $K$. Coronary microcirculation during halothane, enflurane, isoflurane, and adenosine in dogs. Anesthesiology 1992; 76: 261-70.

14 Furchgott $R F$, Zawadzki JV. The obligatory role of endothelial cells in the relaxation of arterial smooth muscle by acetylcholine. Nature 1980; 288: 373-6.

15 Saidman LJ, Eger EI II, Munson ES, Babad AA, Muallem $M$. Minimum alveolar concentrations of methyoxyflurane, halothane, ether and cyclopropane in man: correlation with theories of anesthesia. Anesthesiology 1967; 28:

994-1002.

16 Stevens WC, Dolan WM, Gibbons RT, et al. Minimum alveolar concentrations (MAC) of isoflurane with and without nitrous oxide in patients of various ages. Anesthesiology 1975; 42: 197-200.

17 Katoh T, Ikeda $K$. The minimum alveolar concentration (MAC) of sevoflurane in humans. Anesthesiology 1987; 66: 301-3.

18 Kazama T, Ikeda $K$. Comparison of MAC and the rate of rise of alveolar concentration of sevoflurane with halothane and isoflurane in the dog. Anesthesiology 1988; 68: 435-7.

19 Schnaar RL, Sparks $H V$. Response of large and small coronary arteries to nitroglycerin, $\mathrm{NaNO}_{2}$, and adenosine. Am J Physiol 1972; 223: 223-8.

20 Miwa $K$, Toda $N$. The regional difference of relaxation induced by various vasodilators in isolated dog coronary and mesenteric arteries. Jpn J Pharmac 1985; 38: 313-20.
21 Fam WM, McGregor $M$. Effect of nitroglycerin and dipyridamole on regional coronary resistance. Circ Res 1968; 22: 649-59.

22 Hirakata H, Hatano Y, Ushikubi F, Narumiya S, Mori $K$. Effect of inhalation anesthetics on platelet aggregation-reduction of ligand-binding affinity of platelet thromboxane $\mathrm{A}_{2}$ receptor by halothane. Anesthesiology 1992; 77: A434. 